\section{NSF focuses on sustainability funding}

www.nsf.gov/eng/cbet/suschem
A long with the ever-changing landscape of technology comes a responsibility to develop sustainable practices and materials supplies. From finding substitutes for rare or toxic materials, to discovering new recycling and separation techniques, to developing ways to make manufacturing and other processes more safe and efficient-materials scientists play an important role in sustainability, environmental protection, and responsible stewardship of natural resources.

To better address sustainability issues, the National Science Foundation (NSF) launched the Sustainable Chemistry, Engineering, and Materials (SusChEM) initiative in fiscal year 2013. Creation of the SusChEM initiative was partly driven by a legislative mandate within the America COMPETES Reauthorization Act of 2010. In addition, while NSF has historically supported sustainability-related research, the creation of the SusChEM initiative signals an elevation in the priority of sustainability within the US Federal Government. SusChEM is part of the broader NSF Science, Engineering and Education for Sustainablility (SEES) initative that was extablished in 2010. SEES programs apply science, engineering, and education to address sustainability challenges spanning the range of social, economic, and environmental issues. Funds from SusChEM also partially support some projects within the Networks for Sustainable Molecular Design and Synthesis (NSMDS) effort, a joint initiative between the NSF and the Environmental Protection Agency (EPA). To date, awards funded by the SusChEM initiative support 111 research groups that span 31 states plus the District of Columbia, and represent a capital investment of over \$52.5 million.

Martin Green, Functional Materials Group Leader at the National Institute of Standards and Technology, secured one of the earliest SusChEM grants to help fund a workshop entitled "Sustainability: Building Teams to Tackle Complex Problems." Presented at the 2012 Materials Research Society Fall Meeting, the workshop provided an educa-

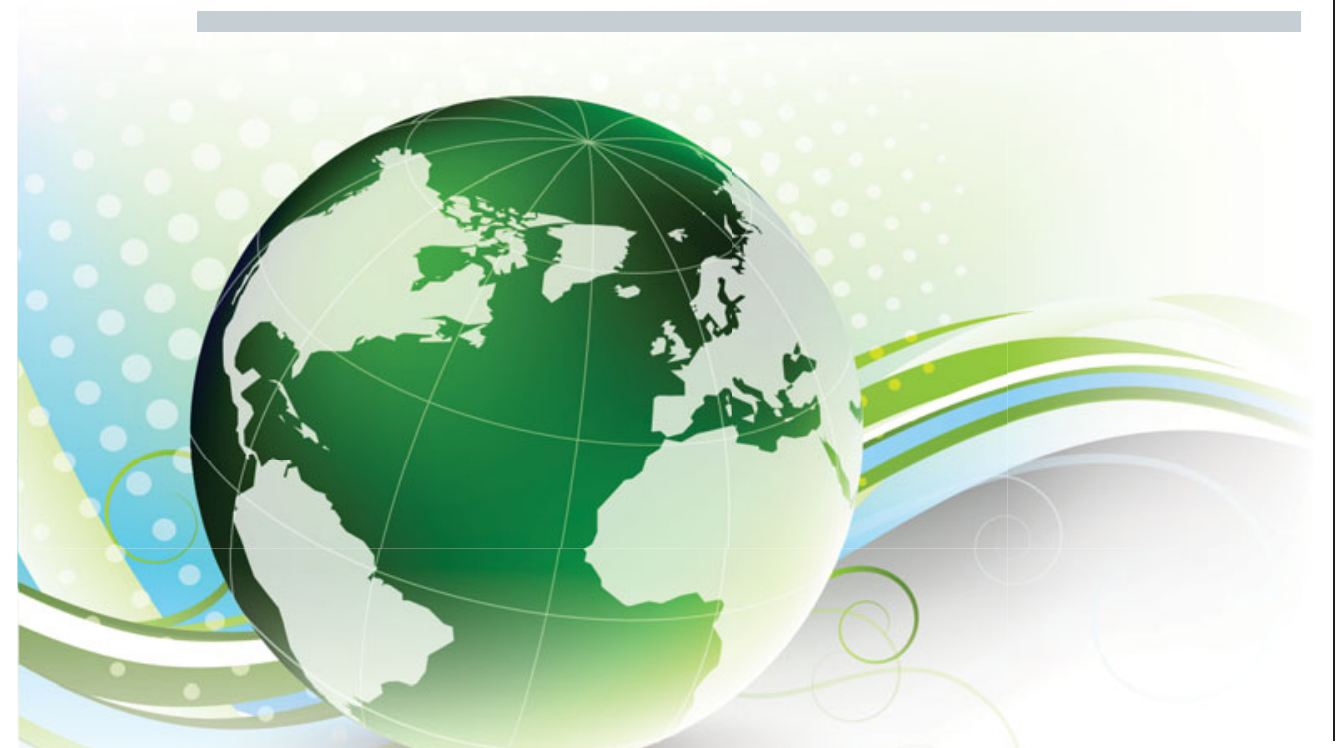

tional platform where researchers could learn about the highly interdisciplinary nature of sustainable development, discuss best practices, and address various complex challenges related to sustainability. Green said that education is key in fostering sustainable development. "It would be appropriate for all human endeavors to be informed by the principles of sustainable development, since none of our planet's resources are infinite," he said.

The SusChEM initiative has provided funds for a broad range of materials and sustainability projects. Alexandra Navrotsky, Distinguished Professor of Ceramic, Earth, and Environmental Materials Chemistry at the University of California-Davis, is working on a SusChEM project to better understand the thermodynamics of minerals containing rare earths. This research should provide fundamental data to guide the development of cheaper, more environmentally friendly methods for extracting rare earths from their ores. According to Navrotsky, the sustainability impacts of this research include "a more stable supply of rare earth elements for applications ranging from magnets in wind turbines to cell phones ... [and] more environmentally acceptable ways of mining and extraction of rare earths."

Yves Chabal, Materials Science and Engineering Professor at the University of Texas at Dallas, is working on a SusChEM project with collaborators in France that focuses on modifying and controlling the interfaces of nanoenergetic materials - materials often used as ignition sources. According to Chabal, current ignition systems are expensive (due to materials scarcity) and rely on synthesis techniques that use or produce hazardous substances. Chabal's research group is developing copperand aluminum-based substitutes that address sustainability in two ways - by eliminating the use and generation of hazardous substances during synthesis and by developing cheap, plentiful, and recyclable materials substitutes. "So, the impact is both on the environment and on addressing sustainability by avoiding depletion of materials that are limited in supply," said Chabal. 
Materials also play a large role in energy sustainability. "Solving the challenges to achieve fully sustainable energy involves coordinated research in many areas," said Veronica Barone, Assistant Professor of Physics at Central Michigan University. Barone is the principal investigator on an energystorage-based SusChEM project that seeks to develop new electrode materials for sodium-ion batteries. The ultimate goal of the project is to replace lithium-ion batteries with reliable sodium-ion substitutes because sodium is abundant and inexpensive. According to Barone, "Lithium cost is skyrocketing and due to its low natural abundance will continue to do so. If we achieve reliable sodium technologies the cost of metal-ion battery technologies will be significantly lower."

Energy is also the focus of Robert Lad's SusChEM project, which seeks to reduce energy consumption in the industrial sector. Lad, Professor of Physics at the University of Maine, is developing a new class of thin-film materials and sensor devices based on multilayered borides, silicides, or oxides integrated with platinum alloys. Lad hopes to produce thin films that are stable in harsh environments and at temperatures above $1000^{\circ} \mathrm{C}$. "The development of stable high-temperature thin films will improve sustainability by enabling the deployment of miniaturized sensors, actuators, and other electronic components that can be used to reduce overall energy usage and increase the longevity of complex, expensive high-temperature machinery," said Lad.

Eray Aydil and Chris Leighton, Chemical Engineering and Materials Science Professors at the University of Minnesota, are using SusChEM funding to research inexpensive, abundant, and non-toxic materials for solar energy conversion. The Minnesota group is examining pyrite (iron disulfide) as an alternative to current thin-film solar technologies. While pyrite is abundant, non-toxic, and cheap, the challenge is producing solar cells that efficiently convert sunlight to energy, a feat that has not yet been achieved with pyrite. While it is impossible to predict the success of pyrite solar cells, Aydil pointed out that the SusChEM project has another very important impact — namely "well-trained students who are sensitized to the importance of looking for sustainable solutions to the problems facing humanity."

Awards for this initiative are typically in the amount of $\$ 300 \mathrm{k}-\$ 550 \mathrm{k}$, depending on the number of investigators and the amount of funds available. Applicants are encouraged to contact a program officer before submitting a proposal.

Jennifer A. Nekuda Malik
Korea reports on 2012 R\&D investments

by private companies

M inister Yoon Sang-jick of the Ministry of Trade, Industry, and Energy and President Jeong Jae-hoon of the Korea Institute for the Advancement of Technology reported the results of their study on the research and development (R\&D) investment trend of the 1000 Korean companies that made

the highest R\&D investments. The total R\&D investment by these top 1000 companies was recorded as KRW35.6 trillion [ USD \$34 billion], up 12.7\% from 2011.

Looking at R\&D investment by sector in 2012, the semiconductor sector was in the lead with KRW12.3 tril-

Table. R\&D Investment and Increase Rate by Sector (KRW billion, \%)

\begin{tabular}{|l|l|l|l|l|l|l|}
\hline Classification & $\mathbf{2 0 0 8}$ & $\mathbf{2 0 0 9}$ & $\mathbf{2 0 1 0}$ & $\mathbf{2 0 1 1}$ & $\mathbf{2 0 1 2}$ & $\begin{array}{l}\text { Compound annual } \\
\text { growth rate } \\
\text { (2008-2012) }\end{array}$ \\
\hline Machinery & $\begin{array}{l}954 \\
(-)\end{array}$ & $\begin{array}{l}896 \\
(6.1)\end{array}$ & $\begin{array}{l}1,058 \\
(18.1)\end{array}$ & $\begin{array}{l}1,192 \\
(12.7)\end{array}$ & $\begin{array}{l}1,410 \\
(18.3)\end{array}$ & $8.1 \%$ \\
\hline Semiconductor & $\begin{array}{l}8,088 \\
(-)\end{array}$ & $\begin{array}{l}8,557 \\
(5.8)\end{array}$ & $\begin{array}{l}10,451 \\
(22.1)\end{array}$ & $\begin{array}{l}11,402 \\
(9.1)\end{array}$ & $\begin{array}{l}12,290 \\
(7.8)\end{array}$ & $8.7 \%$ \\
\hline Auto & $\begin{array}{l}3,734 \\
(-)\end{array}$ & $\begin{array}{l}3,670 \\
(-1.7)\end{array}$ & $\begin{array}{l}4,160 \\
(13.4)\end{array}$ & $\begin{array}{l}4,376 \\
(5.2)\end{array}$ & $\begin{array}{l}4,631 \\
(5.8)\end{array}$ & $4.4 \%$ \\
\hline Electronics & $\begin{array}{l}4,107 \\
(-)\end{array}$ & $\begin{array}{l}4,770 \\
(16.1)\end{array}$ & $\begin{array}{l}6,015 \\
(26.1)\end{array}$ & $\begin{array}{l}5,963 \\
(-0.9)\end{array}$ & $\begin{array}{l}6,864 \\
(15.1)\end{array}$ & $10.8 \%$ \\
\hline
\end{tabular}

lion, followed by the electronics sector (KRW6.9 trillion) and the automobile sector (KRW4.6 trillion). In terms of the year-on-year increase, the machinery sector accounted for $18.3 \%$, followed by the electronics sector $(15.1 \%)$ and the semiconductor sector $(7.8 \%)$.

Of the 2012 total of KRW35.6 trillion invested in R\&D, large-scale enterprises (over 1000 employees) invested KRW30.3 trillion, followed by high potential enterprises (300-999 employees) and smaller businesses (under $299 \mathrm{em}-$ ployees), which invested KRW2.4 trillion and KRW2.8 trillion, respectively.

The year-on-year increase rate in 2012 was recorded as $13.8 \%, 3.1 \%$, and $9.5 \%$ for large-scale enterprises, high potential enterprises, and smaller businesses, respectively.

According to the Ministry, the government will continue to analyze and review the R\&D investment trends of the private sector and reflect the results in R\&D policy establishment.

In tracking global R\&D performance trends, the US National Science Foundation noted in 2011 that South Korea's $\mathrm{R} \& \mathrm{D} / \mathrm{GDP}$ ratio rose to $4.0 \%$. 